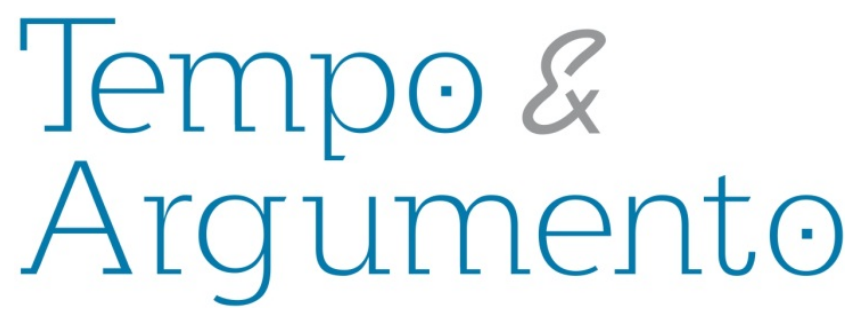

\title{
O lugar do tempo presente na aula de história: limites e possibilidades
}

\begin{abstract}
Resumo
Reconhecendo a importância do tempo presente na conformação da história ensinada e da concepção moderna de história como um todo, o texto delineia a história desta centralidade, associada à tensão entre aproximação inevitável e necessidade de afastamento do enunciado historiográfico em relação à experiência política presente na qual está inserido. Em um segundo movimento, é feita uma análise das perspectivas contemporâneas sobre a questão, levando em conta 1. a ampliação do repertório de sujeitos, objetos e métodos da história, desde a segunda metade do século XX, questionando o paradigma eurocêntrico e a ideia de Civilização que the é intrínseca; 2. a ênfase no conceito de cidadania como mola mestra da historiografia escolar, cuja elasticidade é tributária deste novo arsenal de experiências e narrativas históricas; e 3. a cultura histórica da atualidade e sua ênfase presentista, desconfiada da possibilidade de projeção de futuros estáveis, mas com apreço pela memória e pelo passado em circulação social. Em suma, em face deste contexto de elaboração, difusão e usos de narrativas históricas, o artigo problematiza o lugar ocupado pelo tempo presente em aulas de história na escola, em seus limites e potencialidades. Por um lado, o tempo presente é tido como fundamental para conferir condições de inteligibilidade e produção de sentido histórico, adequado aos objetivos pedagógicos da história e seu propósito formador; por outro, apontam-se os limites de uma ênfase exclusivamente centrada no presente, incapaz de permitir a experiência do descentramento no tempo e a compreensão das permanências, da dimensão cumulativa e da longa duração histórica.
\end{abstract}

Palavras-chave: História - Estudo e Ensino. Historiografia.

Tempo presente.

\section{Para citar este artigo:}

SILVA, Daniel Pinha. O lugar do tempo presente na aula de história: limites e possibilidades.

Revista Tempo e Argumento, Florianópolis, v. 9, n. 20, p. 99 - 129. jan./abr. 2017. jan./abr. 2017.

DOI: $10.5965 / 2175180309202017099$

http://dx.doi.org/10.5965/2175180309202017099 


\begin{abstract}
Recognizing the importance of present time in the conformation of the history taught and the modern conception of history as a whole, the text delineates the history of this centrality, associated with the tension between unavoidable approximation and necessity of distance from history in relation to the political context. In a second movement, an analysis of contemporary perspectives on the issue is made, taking into account 1. the expansion of the repertoire of subjects, objects and methods of history, since the second half of the twentieth century, questioning the Eurocentric paradigm and the idea of Civilization that is intrinsic to it; 2 . the emphasis on the concept of citizenship as the central ideia of school historiography, whose elasticity is doe of this new arsenal of historical experiences and narratives; 3 . the historical culture of the present day and its presentist emphasis, distrustful of stable futures, but valuing the memory and the social circulation of the past in short, in this historiographic context, the article problematizes the place occupied by the present tense in history classes in its limits and potentialities. On the one hand, the place of present tense is elevated as fundamental to confer conditions of intelligibility and production of historical sense, adequate to the pedagogical objectives of history and its formative purpose; on the other hand, the limits of an exclusively centered emphasis on the present are shown, unable to allow the experience of decentering over time and the understanding of permanence, the cumulative dimension and long historical duration.
\end{abstract}

Keywords: History - Study and teaching. Historiography. Present time. 

historiadores, pesquisadores das humanidades, professores de história ou a qualquer estudioso que inclua a história como tema de reflexão. Isto porque, ao enunciar um discurso histórico - seja em forma de pesquisas ou aulas de história academicamente mediadas ou ainda em memórias, exposições em museus, livros ficcionais, produção áudio-visual, conteúdo disponível na internet, entre outros meios de circulação da história - aquele que enuncia se dirige, inevitavelmente, a interlocutores de sua própria época. Decerto que autores e argumentos clássicos conseguem a proeza de atravessar épocas para além da sua, renovando e ampliando o escopo dos interlocutores, mas essa, a rigor, não é uma escolha deliberada deles, mas sim de seus leitores. Certo mesmo é que, ao tornar público algum conhecimento sobre a história, aquele que fala ou escreve se dirige e traz consigo as marcas de sua época, isto é, o tempo presente é uma contínua presença e uma necessidade do discurso historiográfico.

Esta presença do tempo presente pode significar, por outro lado, um limite ao desenvolvimento do conhecimento da própria história, se essa presença significar a completa supressão das diferenças temporais entre presente e passado, tão fundamentais para o estudo da história. A apreensão do passado como diferença está no cerne da conformação da história como área do conhecimento, pois é ela que permite a experiência do descentramento - a saída do próprio centro de produção de sentido -, tão necessária à descoberta do novo que o deslocamento para passado permite. A apreensão plena da diferença temporal surge como meta necessária, ainda que inalcançável, para a tarefa de historiadores, professores e outros especialistas em história. A fuga do presente se torna, assim, condição para pensar historicamente o próprio tempo presente da enunciação, como um campo de possibilidades - e não de determinações - e em suas relações de ruptura e continuidade com o passado.

O lugar do tempo presente em um enunciado historiográfico se apresenta, portanto, como um lugar de tensão, entre a presença e a fuga. Nicole Loraux (1992) parece encontrar uma justa medida para lidar com esta tensão, sem dissolvê-la, ao defender uma prática controlada do anacronismo. Usando como exemplo o estudo da 
É preciso usar de anacronismo para ir na direção da Grécia antiga com a condição de que o historiador assuma o risco de colocar precisamente a seu objeto grego questões que já não sejam gregas; de que aceite submeter seu material antigo a interrogações que os antigos não se fizeram ou pelo menos não formularam ou, melhor, não recortaram como tais. (LORAUX, 1992, p. 61)

Ou seja, é o tempo presente do historiador que elucida as questões que orientam a análise do mundo grego, este mundo aparentemente tão estranho a todos que se debruçaram sobre ele na época moderna. Um mundo irrecuperável em sua plenitude. Neste sentido, indaga Loraux: “Por que milagre - ora, recusávamos o 'milagre grego' de nossos estudos clássicos - podíamos assim ter acesso sem mediação, diretamente e sem distorção, aos pensamentos do homem grego?" (LORAUX, 1992, p. 60). Admitir a dimensão lacunar e irrecuperável deste passado significa colocar em xeque uma concepção de história que se entende capaz de dotar as experiências de um sentido previamente conhecido e plenamente completo, a partir do qual todos os acontecimentos possam se encaixar. Assim, se o anacronismo significa o "pesadelo do historiador, o pecado capital contra o método" (LORAUX, 1992, p. 57), a evidência de incapacidade de manejo com a diversidade temporal, a importação equivocada de noções que sua época de referência não conheceu, ele também abre caminho para a compreensão do conhecimento histórico como algo inacabado, pronto a ser ressignificado a cada novo tempo presente que o mobilize.

Por que fazer o elogio do anacronismo quando se é historiador? Para convidar os historiadores, talvez, a se colocar à escuta de nosso tempo de incertezas, apegando-se a tudo que ultrapassa o tempo da narração ordenada: aos embalos assim como às ilhotas de imobilidade que negam o tempo na história, mas que fazem o tempo na história. (LORAUX, 1992, p. 68) 
A prática de um anacronismo controlado se torna, deste modo, a possibilidade de conformar com equilíbrio a presença inevitável do tempo presente na escrita da história, sem que tal presença represente o congelamento da experiência humana no tempo, a partir de critérios moldados exclusivamente pelo tempo presente da enunciação do discurso historiográfico. Considerando as devidas diferenças de objetivos, alcance e ênfase teórico-metodológica que caracterizam a pesquisa/escrita da história e a história ensinada na escola, mas também as possibilidades de intercessão entre estas duas modalidades de historiografia, propomos aqui que a prática deste anacronismo controlado figure como possibilidade teórica para o professor de história na escola, nos usos do tempo presente empreendidos na aula: eis um primeiro ponto importante de ser retido, a ser retomado ao longo deste texto.

O argumento de Loraux retoma um caminho traçado por Marc Bloch no livro Apologia da História - ou o ofício de historiador, na celebrada formulação acerca da necessidade de "compreender o presente pelo passado e o passado pelo presente" (BLOCH, 2002, p. 25) - aquilo que Jacques Le Goff chamou de método "prudentemente regressivo", espécie de história feita às avessas, ponto caro a Bloch (LEGOFF, 2002, p.25). Neste sentido, estaria incluída no repertório do historiador a tarefa de tradução, isto é, sua capacidade de produzir uma interpretação sobre o passado, dando forma, no presente, a um conjunto diverso e disperso de acontecimentos, indo além do que pareceria evidente através dos documentos ${ }^{1}(\mathrm{BlOCH}, 2002$, p. 142) - guardando, deste modo, lugar central para o tempo presente do historiador, fundamental para a dimensão interpretativa. Mas, para Bloch, há também uma concepção estruturante de homem e de sociedade que atravessa os séculos e produz acúmulo, sem a qual o historiador corre o

\footnotetext{
${ }^{1}$ Tal passo interpretativo definiria uma reivindicada marca de distinção da proposta de nova história trazida pelos historiadores da geração de Marc Bloch - em especial, ele e Lucien Febvre, posteriormente identificados como a primeira geração da Escola dos Annales, reunida desde 1929 em torno da publicação Annales d'Histoire - em oposição aos marcos de uma historiografia positivista, baseada em um pressuposto distanciamento e ocultação interpretativa por parte do historiador, em nome do rigor metódico e do primado da imparcialidade. A esse respeito, ver BURKE, Peter. A Escola dos Annales (1929-1989): a Revolução Francesa da Historiografia. São Paulo: Fundação Editora da UNESP, 1997.
} 
É preciso, claro, no entanto, que exista, na natureza humana e nas sociedades humanas, um fundo permanente, sem o que os próprios nomes de homem e de sociedade nada iriam querer dizer. Portanto, acreditamos compreender estes homens estudando-os apenas em suas reações diante das circunstâncias particulares de um momento? Mesmo para o que eles são nesse momento, a experiência será insuficiente. Muitas virtualidades provisoriamente pouco aparentes, mas que, a cada instante, podem despertar, muitos motores, mais ou menos inconscientes, das atitudes individuais ou coletivas permanecerão na sombra. Uma experiência única é sempre impotente para discriminar seus próprios fatores: por conseguinte, para fornecer sua própria interpretação. [Grifo meu] (BlOCH, 2002, p. 65)

Ainda que a Apologia da História de Bloch seja a apologia do jogo entre passado e presente, tendo em vista a tarefa tradutora e interpretativa do historiador, em diálogo com seu tempo presente, este jogo não pode resultar em uma mera acumulação de presentes que, ao superarem automaticamente seus respectivos passados, se tornam superficialmente descartáveis a cada momento de renovação. Eleva-se, assim, o desafio de produzir outro tipo de deslocamento do tempo presente - além daquele destacado acima, sobre a fuga do presente que produz descentramento -, capaz de evidenciar o que cada presente-passado acrescentou de acúmulo neste "fundo permanente". Será este também um desafio que aproxima a tarefa interpretativa de historiadores acadêmicos e professores de história da escola, levando em conta as peculiaridades que distinguem a tarefa de historiar e ensinar história? Consideramos que sim: eis um ponto fundamental, importante de ser retido e continuamente mobilizado nas linhas deste artigo.

Um terceiro pressuposto salutar, associado aos outros dois e que também atravessa este artigo, diz respeito às especificidades da historiografia escolar e sua interface com os estudos sobre a história da historiografia acadêmica. Consideramos a pertinência do repertório historiográfico acadêmico como parte essencial - mas não exclusiva - da formação do professor de história - tanto a inicial quanto a continuada. Trata-se de um especialista da área que visa à produção do conhecimento histórico a partir de protocolos e objetivos específicos, constituintes da modalidade escolar da 
nacionais e locais, diferentes estágios de formação dos estudantes, saberes apreendidos ao longo da experiência de vida e em sala de aula. ${ }^{2}$ Levando em conta, assim, aquilo que Ana Maria Monteiro destaca acerca da abordagem do presente no ensino da história, em contínuo exercício de recontextualização e hibridização, e em função das particularidades da cultura escolar:

explicações históricas realizadas pelos historiadores, que são necessariamente recontextualizadas e hibridizadas pelos professores nas aulas de história, com aspectos relacionados às referências culturais suas, de seus alunos e do contexto sociocultural mais amplo -, para tornar possível a atribuição de sentidos ao objeto de estudo, em disputa com outros sentidos possíveis, mas fora do controle e do espectro curricular. [Grifo Meu] (MONTEIRO, 2012, P. 195)

Assim, a pesquisa histórica erudita/acadêmica se apresenta como matéria prima sobre a qual o professor pode e deve se debruçar, sem, no entanto, desconsiderar o quadro de referências da cultura escolar a partir do qual o conhecimento sobre a história é inserido e disseminado. Uma formação híbrida, nos termos de Monteiro, tomados de empréstimo de Nestor Canclini (2011): processo que supõe a interação de múltiplos quadros de referência cultural, distantes de uma concepção de pureza ou identidade cultural fixa, sem supor uma relação de assimetria entre os diferentes quadros.

É deste modo que o professor forma uma identidade intelectual que lhe permite tornar-se autor da aula, uma "aula como texto", para usar a importante formulação de Ilmar de Mattos, pois aberta às múltiplas possibilidades de leitura dos atores que se movem no processo de ensino-aprendizagem.

\footnotetext{
${ }^{2}$ Neste sentido, cabe destacar, nos termos de Ana Maria Monteiro, que na experiência da aula o professor mobiliza "saber escolar" - trazendo à tona questões pertinentes à "transposição didática e às mediações entre conhecimento científico e conhecimento cotidiano, bem como às dimensões histórica e sociocultural numa perspectiva pluralista" (MONTEIRO, 2007, p.14) - e "saber docente" - associado a um conjunto mais amplo de saberes, inclusive práticos, que, submetidos a diferentes formas de apropriação configuram uma identidade para o professor. A esse respeito ver MONTEIRO, Ana Maria Ferreira da Costa. Professores de História: entre saberes e práticas. Rio de Janeiro, Editora Mauad, 2007.
} 
A aula de história como texto é criação individual e coletiva a um só tempo; criação sempre em curso, que permanentemente renova um objeto de ensino em decorrência de novas leituras, de outras experiências vividas, da chegada de novos alunos, dos encontros acadêmicos e das conversas com os colegas de ofício, do surgimento de novos manuais didáticos, das decisões emanadas das instâncias educacionais e das questões, dos desafios e das expectativas geradas pelo movimento do mundo no qual vivemos, em sua dimensão local ou global. [Grifo Meu] (MATTOS, 2007, p. 17)

Neste sentido, a aula é resultado de uma experiência coletiva de leitura, marcada pela interação entre professores e alunos e pelo acúmulo de experiências que eles carregam. Está em jogo, neste sentido, a admissão de que a experiência da aula apresenta certa porosidade, movida a partir dos saberes de seus atores - professores e alunos. Trata-se de uma experiência que se cumpre a partir de um processo dialógico, tal qual a relação que se estabelece entre leitores e textos de uma obra aberta, isto é, considerando a recepção (criativa) do leitor como um atributo fundamental. Neste processo, professores e alunos são leitores em diferentes graus, considerando a capacidade de operar com categorias e conceitos próprios à forma da história como campo disciplinar. Se o aluno é leitor, trazendo as marcas da própria experiência histórica vivida individual e coletivamente, e com elas interferindo na aula de maneira criativa, o professor/autor também o é de modo ainda mais intenso: leitor na medida em que se apropria da produção dos pesquisadores especialistas da área de história e dos saberes e erudição acumulados em suas vivências pessoais e intelectuais, ressignificando-os na experiência da aula, em procedimento que envolve um exercício de tradução que é traição, algo bem próximo ao que Marc Bloch defende na operação historiográfica, na medida em que, nos termos de Mattos, "a explicação erudita selecionada e traduzida é transformada em texto de uma aula" e "o texto original já não se distingue por sua intenção original, e sim pela intenção de quem o traduziu” (MATTOS, 2007, p. 13).

O conjunto de questões trazido aqui, acerca dos limites e das possibilidades da problematização do tempo presente na aula de história, reconhece a importância das análises teórico-historiográficas para uma apreensão crítico-reflexiva do conhecimento histórico, em suas múltiplas formas de circulação e apropriação - inclusive a história ensinada. Entendemos que a tematização do tempo presente - de natureza 
eminentemente teórica - nos leva, necessariamente, a uma ênfase que privilegia as contribuições e os enlaces da história da historiografia acadêmica com a historiografia escolar. Tais análises se oferecem aqui como contribuições acadêmicas para a formação intelectual do professor, autor cotidiano de narrativas historiográficas específicas marcadas por processos de recontextualização e hibridização -, em meio às tensões do processo de ensino-aprendizagem - e dos sujeitos nela implicados - e da cultura escolar em que está inserido. Assim, o presente artigo, reconhecendo o manancial teórico aberto pela história da historiografia, recusa qualquer caráter prescritivo, abrindo-se às diferentes formas de tradução por parte dos professores/autores em seus específicos contextos de enunciação.

$\mathrm{O}$ argumento se desenvolve a partir de dois movimentos. No primeiro, destaco o lugar do tempo presente na conformação acadêmico-disciplinar moderna da história e em sua dimensão pedagógica, ressaltando o espaço de tensão - aproximação/afastamento entre estas modalidades e o mundo da política contemporânea que as enforma. No segundo, analiso o estado atual destas questões, levando em conta o novo arsenal teórico e historiográfico acumulado desde a segunda metade do século XX e suas conexões com a história ensinada na escola. Se, de um lado, a formação voltada para a cidadania e o enfrentamento do problema da diferença no mundo contemporâneo, tidos como metas da historiografia escolar, elevam a centralidade do tempo presente na aula de história e, com ela, a necessária prática de um anacronismo controlado - nos termos de Nicole Loraux; por outro, em consideração a estas mesmas metas, ressalvamos a necessidade da produção do deslocamento/descentramento do tempo presente nas aulas de história, visando à compreensão da longa duração e o alcance do fundo comum permanente - conforme Marc Bloch. Um e outro, o jogo entre a presença e a fuga do tempo presente, encerram um procedimento crítico que abre ao professor a possibilidade de lidar com as idiossincrasias da cultura histórica do mundo contemporâneo, marcada, entre outras características, por traços de presentismo na forma de as sociedades lidarem com a experiência do tempo, esvaziamento do lugar da história como área do conhecimento capaz de projetar futuros estáveis e, ao mesmo tempo, notável interesse social pelo passado e multiplicação das formas de circulação dele em diferentes meios. 


\section{O tempo presente e a concepção moderna de história: presença e afastamento da vida política}

O uso da história para a formação de cidadãos na vida política sempre esteve presente e orientou a constituição da história como campo acadêmico-disciplinar e matéria passível de ser ensinada a um auditório mais ampliado de ouvintes e leitores nãoeruditos - caso da aula de história na escola. De acordo com Manoel Salgado Guimarães, pensar o uso da história para fins pedagógicos envolve necessariamente trazer à tona a dimensão política subjacente à escrita e ao ensino da história, identificando as particularidades e demandas sociais que tornam a história um componente obrigatório na composição de um currículo escolar (GUIMARÃES, 2009, p. 37). Ou seja, a história ensinada contém em sua essência a dimensão política que considera o conhecimento histórico - produzido e mediado por pesquisadores e professores - como um conhecimento passível de ser universalizado aos mais diversos tipos de leitores, inscritos no registro escolar e tendo em vista um horizonte comum de formação. Compreende-se, deste modo, a história ensinada como parte de um processo mais amplo na formação dos sujeitos, em que os professores de história assumem um compromisso com o presente e uma responsabilidade política diante do público para o qual se direciona a tarefa formadora.

Isso porque a apresentação desses resultados não é mera decorrência da pesquisa realizada, mas obrigatoriamente deve considerar o público-alvo para o qual os resultados da pesquisa se direcionam. Esse ator deve ser parte ativa nas considerações acerca do uso específico do passado através de uma pedagogia escolar. Nesse sentido, o público alvo, parece claro, não está constituído apenas pelos pares da academia, mas também pelos diferentes públicos que demandam narrativas do passado, entre eles os alunos que devem aprender história nas escolas. (GUIMARÃES, 2009, p. 408)

A presença do tempo presente na constituição do discurso historiográfico está no cerne da constituição moderna da história como área do conhecimento, não apenas em sua modalidade pedagógica. Reinhart Koselleck elucida pontos importantes a este respeito, ao analisar os usos sociais e políticos do conceito de história no contexto de surgimento da experiência contemporânea - virada do século XVIII para o século XIX 
a configuração do conceito moderno, reflexivo de História se deu tanto através de discussões científicas quanto através de diálogos políticosociais do cotidiano. Quem fez a ligação entre os dois níveis de diálogo foram os círculos do Bildungsbürgertum, a assim chamada burguesia culta composta por intelectuais de formação acadêmica, seus livros e suas revistas, que foram aumentando cada vez mais no último terço do século XVIII, sendo seguidos, no século XIX, por inúmeras associações e instituições. O surgimento de uma ciência histórica autônoma pode ser atribuído a essa classe média intelectualizada, a qual, simultaneamente com o desenvolvimento de uma consciência histórica, se aproximava de sua identidade. Nessa medida, a gênese do conceito moderno de História coincide com a sua função social e política - sem naturalmente se limitar a ela. (KOSELLECK, 2013, p. 186)

Deste modo, é possível afirmar que o moderno conceito de história, surgido para dar conta de profundas modificações da experiência histórica, já nasce perfurado por um horizonte político que ultrapassa os limites do debate acadêmico erudito. Tal conceito resulta, também, dos debates político-sociais do cotidiano. Ao tratar de assuntos comuns à vida de muitas pessoas, primando pela narração de experiências históricas passadas, sobre os quais não seria necessário ter domínio prévio de arsenal teórico conceitual, a história se torna suscetível ao debate das opiniões políticas. Afinal, ela fala para e com problemas coletivos que afetam amplas comunidades de leitores e cidadãos, sem que fosse necessário acúmulo de conhecimento prévio e/ou erudição para que o sujeito comum se sentisse afetado pela história. O ensino da história em larga escala surge, neste contexto, a partir da necessidade do Estado de universalizar o conhecimento histórico a um público comum, para além das classes burguesas intelectualizadas: "Tão logo as massas estamentalmente desarticuladas desafiaram para uma nova organização social e política, cresceu o papel do ensino de História" (KOSELLECK, 2013, p. 212). O conceito moderno de história já nasce, portanto, atravessado pelos dilemas e usos políticos do tempo presente.

Em contrapartida, o investimento intelectual em um programa metodológico capaz de conferir à história um estatuto e uma autonomia científica - outra dimensão 
condição para que seu discurso adquira legitimidade científica. A reivindicação de imparcialidade e a ocultação do ponto de vista político do narrador se tornam, neste sentido, primados essenciais para a verdade histórica especializada; é também a condição para que o historiador seja capaz de captar as múltiplas vozes e perspectivas implicadas nas diversas experiências históricas. "O antigo topos de que o historiador deveria ser apolis, isto é, apátrida, para poder servir à verdade e apenas relatar 'aquilo que aconteceu', perpassa, como postulado científico e ético, todos os séculos" (KOSELLECK, 2013, p. 192). Por outro lado, caso privilegiasse o Estado Nacional como protagonista de sua escrita histórica - caso de Leopold Von Ranke, historiador alemão visto hoje como protótipo do historiador cientificista dos oitocentos, e de tantos outros - este historiador moderno oitocentista se colocaria diante de uma ambivalência: afinal, a afirmação da nação como entidade capaz de unificar as coletividades em torno de um sentimento comum, produzindo uma identidade, também não pode ser considerada uma invenção de sua época, revelando um uso político da escrita da história e em conexão com o presente? É plenamente possível o afastamento do historiador das posições do conflito impostas pelo tempo presente? Ricardo Benzaquen de Araújo toca precisamente neste ponto, ao tratar da relação entre imparcialidade e perspectiva intelectual como ponto de tensão permanente da escrita da história moderna - persistente, ainda, nos dias de hoje:

A imparcialidade, a objetividade, em suma, o afastamento do historiador das diversas posições de conflito parece ser um dos pressupostos centrais desta concepção moderna de história. Entretanto, antes mesmo da eclosão da Revolução Francesa, autores vinculados ao iluminismo alemão, como Chladenius, já chamavam a atenção para a virtual impossibilidade de se atingir o ideal de um distanciamento absoluto pois, porque se conseguisse afastar o historiador das suas lealdades políticas e religiosas, ele ainda estaria enfocando seu objeto a partir de um determinado ponto de vista, de uma perspectiva intelectual específica que faria com que ele enfatizasse tal aspecto e outro, dirigisse a pesquisa em direção a uma e não em outra, e assim por diante. (ARAUJO, 1988, p. 33) 
Delineia-se, assim, o ideal de uma verdade exata, rigorosa, que se revelaria não mais em nome dos debates éticos que as ações humanas possibilitam, mas apenas pela preocupação em verificar se, quando e onde elas efetivamente existiram (ARAUJO, 1988, p. 30). A história se afirma como a ciência capaz de criar regularidades onde reina o império da contingência, isto é, nos acontecimentos do passado. Convive, no entanto, com o pressuposto antigo de que ela apura o particular, isto é, aquilo que se torna notável no passado e é digno de ser lembrado. E se o passado oferece variáveis infinitas de acesso, a possibilidade de ordenamento deste caos se estabelece 1. por meio da conformação de um método comum para acessá-lo, dotando-o de verdade; e 2. por meio da definição de um sentido narrativo, estabelecido, a partir da experiência do tempo presente de enunciação do texto (ARAUJO, 1998, p. 232).

No caso brasileiro, a escrita da história, em especial concentrada no Instituto Histórico e Geográfico Brasileiro - fundado em 1838 com o propósito de dar forma à história nacional -, privilegiava a construção de uma identidade nacional coesa, capaz de abafar as diversidades regionais e étnicas (GUIMARÃES, 1988; ARAUJO, 2008). Ou seja, incorporava à escrita da história demandas políticas dos grupos hegemônicos que controlavam o Estado Brasileiro recém independente do domínio português, notadamente de duas formas: 1. pela submissão da diversidade regional, marca da experiência colonial, ao domínio do nacional; e 2. por meio da hierarquização das diferenças raciais e étnicas, de modo que a nação brasileira, com privilégio da herança europeia, pudesse se sobrepor às nações indígenas e africanas que habitavam o território colonial (MATTOS, I, 2009)

\footnotetext{
${ }^{3}$ De acordo com Ilmar de Mattos (2009), a escrita da história especializada respondia, em grande medida, a uma demanda política dos grupos políticos que mantinham o Estado sob o seu controle, uma demanda estabelecida no tempo presente: a instituição de uma expansão para dentro de valores nacionais e símbolos nacionais. Diante do reconhecimento de que a independência política não tivera despertado espontaneamente sentimento nacional e que a "causa do Brasil" era, na década de 1820, circunscrita a um grupo localizado no centro-sul do território, a elite político-econômica localizada nesta mesma região, controladora do Estado pós-independente, impõe às demais a sua expansão, transformando em interesse nacional o que era de interesse do grupo. A esse respeito, ver MATTOS, Ilmar R. Do Império do Brasil ao Império do Brasil In: Faculdade de Letras da Universidade do Porto (Org.). Estudos em homenagem a Luís Antonio de Oliveira Ramos. Porto: Universidade do Porto, 2004, v. 2, p. $727-736$ e MATTOS, Ilmar R. de. O gigante e o espelho In: GRINBERG, Keila e SALLES, Ricardo (Org.). O Brasil Imperial (1831-1870). v.2. Rio de Janeiro: Civilização Brasileira. p.13-51. 2009.
} 
A adesão de homens de letras especialistas em história a este projeto ocorreu de diversos modos, e de maneira mais ou menos intensa ${ }^{4}$ : comum a todos era a reivindicação de imparcialidade, abstração e afastamento do tempo presente como critérios essenciais ao estabelecimento da verdade histórica. O método ocupava, nesse sentido, um papel fundamental de instância neutralizadora da dimensão política subjacente à tarefa de narrar a história do Brasil. Como destaca Rodrigo Turin, ao analisar o ethos do historiador brasileiro oitocentista:

O método serve aqui como uma instância neutralizadora, a qual permite que o autor proclame seus valores sem que estes, teoricamente, influam nos resultados de seus estudos. O posicionamento, nessa perspectiva, é uma condição do conhecimento histórico, não interferindo, contudo, na validade desse conhecimento. O método que o autor se impõe serve, de um lado, como meio racional de construção de conhecimento, e, de outro lado, como arma de legitimação nos combates letrados (o último método é sempre o que detém mais capital de persuasão). Ambas as facetas se reenviam uma à outra, são partes constituintes dessa experiência. A retórica cientificista procura garantir para o enunciado um efeito de verdade; e o faz tanto pela simples explicitação dos critérios "científicos" e pela citação de autores estrangeiros, como pelo modo de "colocar em narrativa" a evolução do processo histórico. (...) É pelo método que o autor procura garantir a verdade de sua enunciação e que pode nomear-se histor: eu digo e baseio o que digo pelo método. Mediante esta retórica, ele pretende antecipar no leitor uma cisão fundamental que garanta a legitimidade do enunciado histórico frente aos juízos políticos, seguindo aquela mesma fórmula pregada por Martius: agradar não menos ao coração que à inteligência (TURIN, 2009, p. 23)

Na modalidade pedagógica, este anseio de neutralidade por meio da cisão entre enunciado histórico e juízo político mostrava-se como uma pretensão ainda mais distante de ser concretizada. No contexto imediatamente posterior à independência política brasileira, a historiografia escolar esteve associada diretamente a um processo de formação de cidadãos para a chamada "boa sociedade oitocentista", tendo em vista a

\footnotetext{
${ }^{4}$ A esse respeito, ver: CEZAR, Temístocles. Lição sobre a escrita da história. Historiografia e nação no Brasil do século XIX. Diálogos (Maringá), Maringá - Paraná, v. 8, p. 11-29, 2004 e SOUSA, Francisco G. Revolta e proclamação como molduras da história: escrita da história e olhares para a República entre os sócios do IHGB História da Historiografia, Ouro Preto, n. 18 , agosto 2015 p. 213-230
} 
concepção restritiva de cidadania característica do modelo político presente no Império do Brasil: um cidadão civilizado e capaz de aceitar e reproduzir as hierarquias que compunham aquele modelo de sociedade (SALLES, 1996; MATTOS, H., 2009). O paradigma de cidadania estabelecido pela Constituição brasileira de 1824 assegurava como critérios fundamentais para o exercício pleno da cidadania a liberdade e a propriedade. Ao manter boa parte da população em cativeiro, com a persistência da escravidão, o regime político assegurava aos senhores o predomínio do seu direito de propriedade em detrimento da liberdade irrestrita de todos os habitantes do Brasil. Desse modo, tanto liberdade como cidadania seriam privilégios assegurados por vínculos de nascimento. Cidadão pleno é aquele que consegue combinar liberdade e propriedade, podendo exercer dos direitos políticos plenos, de votar e candidatar-se para cargos provinciais, de acordo com as posses comprovadas. É ele quem constitui a chamada "boa sociedade", aquela que governa e ordena a sociedade, interlocutor privilegiado do Estado. Os sujeitos sem propriedade, mas com liberdade, os chamados "homens livres e pobres", compunham uma camada intermediária, desfrutando de direitos civis, mas sem acesso pleno aos direitos políticos; enquanto que os escravos, pertencentes ao mundo do trabalho, não eram considerados cidadãos, pois desprovidos de liberdade e da propriedade do próprio corpo (MATTOS, I., 2004). Tanto a escrita da história quanto a história ensinada estariam, neste sentido, à disposição dos interesses da "boa sociedade", em função da formação de seus cidadãos.

Por outro lado, era necessário urdir, igualmente, uma unidade nacional "voltada para fora", mais especificamente em direção à Europa Ocidental: forjar-se como nação próspera, independente e civilizada, nos termos do novo repertório de ideias ocidentais proliferadas desde a Revolução Francesa. Neste sentido, a inserção do Brasil na Civilização Ocidental ocupava as preocupações centrais de programas didáticos da área de história, visando à formação de cidadãos da boa sociedade - inclusive por meio de trajetórias biográficas exemplares - conferindo ao público escolarizado uma identidade comum por meio da história ensinada. A esse respeito afirma Marcelo Magalhães: 
A história do Brasil como disciplina distinta da história da civilização só surgiu em 1895. Era caracterizada pela cronologia política e pelo estudo da biografia de brasileiros ilustres, além de acontecimentos considerados relevantes para a afirmação da nacionalidade. Cabia à história como disciplina escolar: construir a memória da nação como uma unidade indivisível e fornecer os marcos de referência para se pensar o passado, o presente e o futuro do país. (MAGALHÃES, 2003, p. 169)

A pergunta central que associa a história a seus usos pedagógicos, sociais e políticos - se quisermos retornar ao ponto inicial - é acerca do tipo de cidadão que se pretende formar, levando-se em conta o público para o qual os resultados se direcionam. Quando esse público se amplia para além dos pares acadêmicos, daqueles que se dedicam à escrita da história pelo interesse no desenvolvimento dessa área de conhecimento, a história se torna mais permeável, em função das demandas de seus múltiplos leitores - ainda que a modalidade estritamente acadêmica queira distância. Mesmo que neste primeiro momento, nos oitocentos, estes leitores pertençam a um grupo bastante restrito da sociedade, a própria transformação da história em matéria ensinável já altera o seu estatuto, em função das diferentes necessidades de seu público ouvinte e leitor - ainda que sob mediação e intervenção mais imediata do Estado, ordenador dos programas curriculares da área. Em suma, uma história que, à disposição do público que a apreende, acadêmico ou escolar, carrega em seu âmago as marcas de uma relação tensa com o tempo presente e com a presença da vida política.

\section{Tempo presente como contínua presença e como limite à aula de história:}

\section{perspectivas contemporâneas}

As novas experiências que caracterizam a modernidade tardia, e que desde então não cessaram de se ampliar e aprofundar, também marcavam fortemente outros historiadores, em que pesem as diferenças entre os mesmos. Ao fim e ao cabo era a própria oficina da história que se transformava. Experiências que, além de incidirem sobre a própria explicação erudita da história, também se manifestam de modo agudo nas experiências vividas por homens e mulheres em todos os quadrantes. De modo cada vez mais acelerado, deslocam-se os modelos europeus de cultura; os Estados Unidos o centro de produção e circulação global de 
cultura; e a descolonização do Terceiro Mundo faz emergir as sensibilidades descolonizadas. Sob o impacto da globalização e da compreensão das dimensões espaço-temporais, os três grandes pilares da identidade e da cultura nacionais - as grandes narrativas da história, da língua e da literatura - são cada vez mais postos em questão. Produzem-se novas identidades, ao mesmo tempo em que novos sujeitos emergem no cenário político e cultural. A abertura para a diferença e o progressivo deslocamento em direção às margens revelam novos atores $e$ autores. [Grifo Meu] (MATTOS, I., 2007, p. 10)

$\mathrm{Na}$ análise de Ilmar de Mattos encontramos, mais uma vez, um bom ponto de partida para o tratamento da nossa questão: em destaque, as mudanças operadas na 'oficina da história' desde a segunda metade do século XX. Trata-se de um conjunto de experiências históricas que orientaram mudanças na percepção do conhecimento histórico e nos seus procedimentos de escrita e ensino da história, em mais uma evidência de quanto a produção historiográfica é atravessada por experiências políticas dos tempos presentes que lhe dão forma. A produção de novas identidades, deslocadas do centro de referência do "homem europeu branco ocidental" - como critério exclusivo para a definição do paradigma de história ocidental -, parece ser a marca deste tempo de giro em direção às margens, pondo em relevo novos atores e autores. Neste sentido, a abertura para a diferença se apresenta como uma necessidade. Um quadro que desestabiliza, mas ainda não inverte, e tampouco dissolve as relações entre centro e periferia. Daí que a emergência deste tempo de sensibilidades marginais carrega novidades que ainda não superam ou substituem inteiramente o paradigma de universalidade posto em questão, mas, certamente, provocam uma tensão impossível de ser ignorada.

Beatriz Sarlo chamou a atenção para a guinada subjetiva possibilitada por tais mudanças na "oficina da história". A autora argentina chama a atenção para a existência de um movimento da área da história e de outras ciências humanas em direção à história de sujeitos comuns e marginais, e de coletividades que não se inserem em um paradigma a partir do Estado e ou da Nação. As mudanças nos objetos da história acadêmica se notaram de maneira mais acentuada na chamada história social e cultural, que deslocou seu estudo para as margens das sociedades modernas, modificando a noção de sujeito e 

vezes, têm alcance público e extracurricular.

Tomando-se em conjunto essas inovações, a atual tendência acadêmica e do mercado de bens simbólicos que se propõe a reconstruir a textura da vida e a verdade abrigada na rememoração da experiência, a revalorização da primeira pessoa como ponto de vista, a reivindicação de uma dimensão subjetiva, que hoje se expande sobre os estudos do passado e os estudos culturais do presente, não são surpreendentes. São passos de um programa que se torna explícito, porque há condições ideológicas que o sustentam. Contemporânea do que se chamou nos anos 1970 e 1980 de 'guinada linguística' ou muitas vezes acompanhandoa como sua sombra, impôs-se a guinada subjetiva. (SARLO, 2007, p. 18)

As grandes narrativas da história - centradas na associação entre processo e progresso e numa ideia de Civilização que confere lugar especial à Europa Ocidental, centro e polo irradiador de valores universais, herdadas da llustração, da Revolução Francesa e da expansão imperialista cientificista do último quarto do século XIX (STAROBINSKI, 2001) - pareciam não dar mais conta das mudanças operadas destas novas “oficinas da história”. Decerto que as experiências das Grandes Guerras ocorridas em pleno solo europeu na primeira metade do século XX já puseram em questão a validade deste modelo de Civilização, trazendo à tona a barbárie da destruição humana em massa, com aparato tecnológico e em nome do progresso (ARENDT, 2003). Walter Benjamin, ainda em 1940, refletindo sobre este mundo em dissolução em suas teses "Sobre o conceito de História", já revelava os limites da crença cega no progresso como motor da história - em suas palavras, "não há documento de cultura que não seja também documento de barbárie" (BENJAMIN, 2013, p. 13) - e do privilégio unilateral do ponto de vista dos vencedores na perspectiva adotada pelos historiadores historicistas (BENJAMIN, 2013, p. 12), insensíveis aos dilemas do presente (BENJAMIN, 2013, p.19). Além disso, o contexto imediatamente posterior à Segunda Guerra Mundial, marcado pela denúncia pública do Holocausto, centrada em relatos testemunhais dos seus sobreviventes, evidenciaria ainda os limites deste modelo, ressaltando a pergunta sobre 
como dar forma e inteligibilidade histórica a eventos traumáticos de um passado recente e com feridas em aberto - conforme ressaltado por Beatriz Sarlo no trecho acima.

A complexidade de experiências históricas como a Segunda Guerra Mundial, o PósGuerra e a Descolonização da África ressalta a insuficiência de formas historiográficas centradas: 1. de um ponto de vista temático, em histórias de Estados Nacionais ocupadas em dirimir as diferenças em nome de identidades nacionais uniformizadoras, e conectadas por uma concepção processual de Civilização - produtora de naturalizações, como a do desenlace do progresso e das hierarquias entre centro e periferia; e 2. de um ponto de vista metodológico, no questionamento da exclusividade do uso de textos escritos como fontes documentais de referência, do fato de que a história trate apenas de "passados-perfeitos", plenamente encerrados. Como desdobramento de tais questionamentos, evidencia-se a desestabilização do princípio historiográfico moderno conforme traçado na seção anterior - que defende a necessidade de afastamento do historiador em relação ao seu tempo presente ${ }^{5}$.

De um ponto de vista epistemológico, o alcance do chamado giro linguístico no âmbito do conhecimento histórico ${ }^{6}$ também ressalta a insuficiência do paradigma historicista e o redimensionamento do lugar do tempo presente na produção

${ }^{5}$ É sintomático, neste sentido, o crescimento da história do tempo do presente como campo teóricometodológico específico de investigação. A criação do IHTP Institut d'Histoire du Temps Présent, em Paris, em 1978, pode ser considerada um marco destas aspirações, reunindo em um setor específico pesquisadores, obras, simpósios e metodologia, em suma, uma massa crítica para delinear os termos de uma investigação histórica sobre o tempo presente (FERREIRA, 2000; FERREIRA e DELGADO, 2013). Cumprem papel semelhante publicações como a revista francesa Vingtième Siècle, posta em circulação em 1984, e o inglês Journal of Contemporary History, de 1996 (DOSSE, 2012).

${ }^{6}$ Como explica Rogério F. da Silva, a expressão giro linguístico foi utilizada inicialmente no contexto da tradição da filosofia analítica anglo-saxônica, visando destacar que muitos dos problemas filosóficos poderiam ser tratados como problemas no âmbito da representação do mundo por meio da linguagem. (SILVA, 2015, p. 383). No campo da história, este debate ganha forma na década de 1970, com as repercussões da obra do historiador norte-americano Hayden White. Nas palavras de Silva, "já podemos afirmar que se estabeleceu um relativo consenso em associá-lo a Hayden White (...), e este consenso se deve ao fato de que, o que era até então uma discussão mais diretamente associada à filosofia da linguagem, de tradição anglo-saxônica (...), aos desenvolvimentos da linguística, e a pensadores franceses, especialmente os citados Jacques Derrida e Roland Barthes, agora passava também a dizer respeito à história. Hayden White, inspirado nesses autores bem como na teoria e crítica literária (especialmente na obra de Northrop Frye [FRYE, 1973]), trouxe esta questão para o campo da história com uma obra sobre historiadores e filósofos da história do século XIX em sua obra Metahistória. A sua afirmação de que o texto histórico não passa de um "artefato literário" (...) a partir da perspectiva do giro linguístico veio, com razão, provocar variadas reações entre os historiadores (...)" (SILVA, 2015, p. 383). 
historiográfica. Primeiramente, o debate em torno do giro linguístico coloca em xeque 1. a possibilidade de que o fato histórico seja transparente em relação à experiência histórica, isto é, que não haja mediação interpretativa e subjetiva na operação historiográfica; e 2. que ao historiador seja possível restituir uma verdade total sobre a realidade tal como ela foi. Tal constatação não implica a decisão de afastar a história da referência do mundo real, mas o destaque para que os postulados historiográficos sejam mediados por discursos e por formas que também conhecem uma historicidade. Para Roger Chartier, o giro linguístico reforçou o pressuposto de que a realidade não é uma referência objetiva, externa ao discurso, mas é sempre construída em e através da linguagem (CHARTIER, 2002). Em segundo lugar e, por conseguinte, se mediado pela linguagem, o acesso ao real carrega, inevitavelmente, os pressupostos do mundo de sua formulação, isto é, o acesso ao real traz consigo as marcas do tempo presente que o projetou. Oportunamente, Marcelo Rangel e Valdei Araújo (2015) identificam no debate sobre o giro linguístico um ponto de abertura para que a historiografia contemporânea, pós-giro, enfatize a dimensão ético-política que constitui os enunciados historiográficos.

As reflexões e compreensões disponibilizadas a partir do giro linguístico apontam para a constituição de um horizonte comum no interior da teoria e da história da historiografia contemporâneas, a saber: (1) o sujeito do conhecimento não pode produzir enunciados privilegiados em relação à realidade, a despeito das teorias e métodos em questão e (2) a historiografia possui uma determinação específica, a de pensar e/ou intervir no mundo que é o seu. (...) Não obstante os argumentos que possamos utilizar, quer favoráveis ou contrários a esse horizonte, parece que o mundo contemporâneo, posterior ao giro linguístico, tornou-se profundamente crítico de toda e qualquer argumentação fundada na possibilidade da produção de enunciados privilegiados em relação ao real, de modo que podemos acompanhar certa consequência mais propriamente geral provocada pelo giro linguístico no interior da teoria e da história da historiografia contemporâneas, a saber, a sua fundamentação ou mesmo justificativa ético-política (e, aqui, "ética" significa pensar seu mundo e "política", algo como uma intervenção mais imediata e pró-ativa). (...) (ARAUJO e RANGEL, 2015, p. 328)

Isto que os autores estão chamando de giro ético-político, identificado como uma tendência historiográfica contemporânea, expressa no objetivo de "pensar e/ou intervir 
no mundo que é o seu", traz em seu bojo a centralidade da problematização do tempo presente e da dimensão política subjacente ao discurso historiográfico no momento de sua enunciação e de sua leitura - ainda que, cabe ressaltar, tal dimensão não seja capaz de encerrar todos os objetivos e pretensões da produção do conhecimento crítico sobre a história.

Ao destacar as implicações políticas contidas no discurso historiográfico, esta tendência se mostra afinada ao modo de ser da história ensinada, oferecendo-se à tradução - para usar os termos de Ilmar de Mattos sublinhados na introdução deste texto - por parte de professores de história em contextos específicos de produção do conhecimento histórico. Afinal, conforme destacado na nossa seção anterior, está no cerne da modalidade pedagógica da história o seu propósito formador de condição comum a todos os cidadãos, qual seja, a de pensar e intervir no tempo presente por meio do conhecimento produzido sobre a história. Constitui componente central da história ensinada este direcionamento à compreensão da complexidade e dos problemas do tempo presente, suprindo carências conceituais de orientação do mundo e rompendo com possíveis naturalizações. A passagem de Teixeira, Magalhães e Rocha é elucidativa neste sentido:

O conhecimento a que ela [história escolar] visa tem relação com o objetivo de fundo de toda historiografia: suprir a carência de orientação no mundo. Para tanto é preciso construir leituras sobre o mundo e sobre si capazes de favorecer o sentimento de identidade (por conseguinte, de pertencimento) e, ao mesmo tempo, a capacidade crítica para reconhecer e lidar com as diferenças e situa-las no tempo (ou seja, situálas historicamente). Nesse sentido, pode-se dizer que o objetivo da história escolar é ensinar/aprender a pensar historicamente, rompendo com as naturalizações e abrindo o horizonte de expectativas. (TEIXEIRA, MAGALHAES E ROCHA, 2009, p. 16)

Diante do quadro de experiências históricas que afetaram a "oficina da história" na segunda metade do século XX - marcado, como vimos, pela desestabilização de pressupostos do paradigma eurocêntrico/civilizado e por uma abertura à diferença, pondo em relevo novos personagens e em perspectivas metodológicas distintas do paradigma historicista - a pergunta pelo sentimento de identidade e pela abertura de 
Mola mestra da história escolar brasileira desde os seus primórdios, conforme visto na seção anterior, o conceito de cidadania possui centralidade nos objetivos curriculares do ensino da história ainda nos dias de hoje. No entanto, há no tempo presente uma condição específica para o desenvolvimento da ideia de formação e formação para a cidadania; ou ainda, a própria ideia de formação, a partir do ensino de história, se modificou em função de novas demandas sociais, pedagógicas e do campo específico do conhecimento histórico - também em função das novidades na "oficina da história”. Nem a noção de cidadania política é a mesma do século XIX, nem as categorias disponíveis para a sua análise o são. Trata-se, agora, de uma cidadania ancorada na necessidade de ampliação de vozes, de sujeitos e movimentos sociais, e, por isso, já não é mais possível defender que a realização da aula de história esteja calcada apenas no desenvolvimento do Estado Nacional e da produção de uma identidade nacional una a partir dele. Os sujeitos narrados na aula são novos e o professor de história tem à sua disposição um repertório amplo de reflexões acadêmico-historiográficas e experiências históricas do mundo político - como depreendemos da leitura de Beatriz Sarlo - capazes de dotar tais ações de maior complexidade e grau de desnaturalização.

Podemos considerar que os Parâmetros Curriculares Nacionais, lançados em 1997, um ano após a promulgação da Lei de Diretrizes e Bases da Educação Nacional, repercutem inteiramente essas mudanças. Documento importante do momento político brasileiro vivenciado no país no pós-Constituição de 1988, os PCNs incorporam em seu bojo o paradigma democrático instituído pela Carta, afirmando como fundamentos essenciais à democracia brasileira a defesa das liberdades civis e políticas, os direitos sociais garantidos pelo Estado, o reconhecimento das diferenças culturais e da pluralidade como marcas constituintes da formação social brasileira; ou seja, além da garantia da liberdade e da defesa da diminuição das desigualdades sociais, esta concepção de democracia incorpora, de maneira decisiva, a pluralidade. As propostas em relação à educação como um todo, e ao ensino da história em específico, refletem 

políticas, disputa cotidianamente a cidadania.

De acordo com Circe Bittencourt, os PCNs destacam que entre os objetivos centrais do ensino de História está a contribuição na construção de identidades, no plural (BITTENCOURT, 2004, p. 121), apontando para formas de atuar e contribuir com a conformação de um espaço público marcado pelo signo da diferença e por modos de lidar com ela. Constrói-se, assim, um modelo de cidadania que se fundamenta também nas singularidades e no respeito pelas diferenças étnicas, religiosas, sexuais, de gênero, marcantes na nossa sociedade. De acordo com Marcelo Magalhães, partindo de um diagnóstico negativo e incompleto do funcionamento da cidadania no Brasil caracterizado pelo "desemprego, a segregação étnica e religiosa (...) ausência de ética nos meios de comunicação de massa; e crescimento da violência e da criminalidade" (MAGALHAES, 2003, p. 176), os PCNs sugerem que o ensino da história possa tanto refletir crítica e historicamente sobre esses problemas, como apontar para soluções coletivas para a superação deles. Há associação entre democracia e cidadania, e "esta adquire novas dimensões, englobando os direitos sociais e os direitos humanos" (MAGALHAES, 2003, p. 177), ou seja, considera tanto a perspectiva da cidadania pela via da história da ampliação dos direitos, e da universalização dos direitos ao longo do tempo, como a concepção de cidadania fundada no direito à diferença (MAGALHAES, 2003, p. 180). Em suma, no cerne da proposta central dos PCNs está a sugestão de que as aulas de história abordem a história do conceito de cidadania tendo em vista uma prática controlada de anacronismo - para lembrar dos termos de Nicole Loraux.

É considerando, entretanto, esta mesma particularidade da história escolar em "reconhecer e lidar com as diferenças e situá-las no tempo" - retomando as palavras de Teixeira, Magalhães e Rocha - que consideramos importante preservar o lugar do tempo presente na aula de história de um uso indiscriminado.O desafio de pensar a história para além do presente inclui não só a necessidade de estabelecer com o passado uma relação de alteridade, desvendando-o em sua lógica própria, mas também as possíveis relações 
de continuidade entre passado e presente. Ou seja, o tempo presente, marcado pela coexistência de extratos temporais de curta, média e longa duração, é resultado das rupturas que o distinguem e das continuidades geradas pelo acúmulo das experiências passadas (BRAUDEL, 2007; KOSELLECK, 2014).

O reconhecimento destas distinções compõe o arsenal teórico fundamental dos especialistas em história, e o domínio de tais categorias se torna ainda mais imperativo se problematizarmos alguns dos modos pelos quais a experiência do presente e as representações sociais do passado têm circulado em âmbito público no contexto contemporâneo - em espaços para além do acadêmico e do escolar, mediados por especialistas como historiadores e professores de história. Voluntária ou involuntariamente, a aula de história é entremeada pela cultura histórica de sua época, entendendo o termo cultura histórica conforme sintetizado por Fernando Sanchez Costa, ou seja, como "conjunto de recursos e práticas sociais através dos quais os membros de uma comunidade interpretam, transmitem, materializam e transformam seu passado" (COSTA, 2009, p. 277). Neste sentido, o professor, autor da aula, encontra diante de si um estudante afetado pelas múltiplas formas de circulação do passado, anteriores e posteriores ao momento da aula, das quais é possível citar: relatos orais, museus, romances históricos, filmes, programas televisivos, mídias sociais e todo o conteúdo disseminado na internet; materiais diversos e que conferem múltiplas significações ao passado, algumas distorcidas, falsificadas ou sem autoria, elevando a responsabilidade e a condição autoral/intelectual do professor a partir das condições específicas de enunciação da sua aula.

Autores como François Hartog (2014), Andreas Huyssen (2000) e François Dosse (2012) - para citar três exemplos relevantes em circulação no debate historiográfico acadêmico atual7 - têm destacado as percepções e as formas de experimentar o tempo e as articulações entre passado, presente e futuro em sociedades contemporâneas. A despeito das diferenças interpretativas e de ênfase na análise é possível identificar nos três um diagnóstico comum: as sociedades contemporâneas têm experimentado uma

\footnotetext{
7 Neste sentido também é fundamental a referência aos trabalhos de Hans U. Gumbrecht, com ampla circulação no debate acadêmico atual.
} 
compreendido como mera passagem entre o passado e o futuro, adquirindo uma configuração própria e alargada.

Nos termos de Hartog, "O presente tornou-se o horizonte. Sem futuro e sem passado, ele produz diariamente o passado e o futuro de que sempre precisa, um dia após o outro, e valoriza o imediato" (HARTOG, 2014, p. 148). A elevação do lugar do presente é decorrência, segundo Hartog, do declínio de ideologias e da descrença na possibilidade de o presente produzir antecipação em relação ao futuro, marcantes nas sociedades contemporâneas desde o fim da experiência histórica da Guerra Fria - tendo como baliza simbólica a queda do Muro de Berlim em 1989. O presentismo, neologismo formulado pelo historiador francês, é sintoma de uma época marcada por um presente hipertrofiado pelas necessidades da sociedade de consumo, de aceleração do tempo imposta pelos meios de comunicação de massa, pela internet, em suma, pela efemeridade e superficialidade das relações sociais:

as inovações tecnológicas e a busca de benefícios cada vez mais rápidos tornam obsoletos as coisas e os homens, cada vez mais depressa. Produtividade, flexibilidade, mobilidade, tornam-se as palavras-chave dos novos administradores. Se o tempo é, há muito, uma mercadoria, o consumo atual valoriza o efêmero. A mídia, cujo extraordinário desenvolvimento acompanhou esse movimento que é, sem sentido próprio, sua razão de ser, faz a mesma coisa. Na corrida cada vez mais acelerada para o ao vivo, ela produz, consume, recicla cada vez mais palavras e imagens e comprime o tempo: um assunto, ou seja, um minuto e meio para trinta anos de história. (HARTOG, 2014, p. 148)

Tal presente alargado não apresenta, como decorrência, um esvaziamento do passado como produtor e multiplicador de sentidos: há presença marcante do passado nos espaços públicos e uma guinada de interesse pela memória e pela patrimonialização, trazendo à tona a necessidade de promover distinções e peculiaridades culturais, em face de tendências homogeneizadoras da cultura capitalista globalizada. Andreas Huyssen 
examina o surgimento de uma sociedade contemporânea de "seduzidos pela memória" que produziu um deslocamento do futuro-presente modernista ao passado-presente memorialista (HUYSSEN, 2000, p. 10). Um movimento com alcance geográfico amplo e pleno de sentidos políticos, como são os casos das políticas da memória em regimes pósditatoriais na América Latina, com vistas ao esforço induzido por governos democráticos "para que nunca se esqueça, para que nunca mais aconteça", lema das campanhas por memória, verdade e justiça. Estas culturas da memória são enormemente influenciadas por seus meios de disseminação pública e aparato tecnológico e midiático, prontos a potencializá-las - e também a comercializá-las como mercadoria, objeto de consumo (HUYSSEN, 2000, p.21).

No trecho abaixo, de François Dosse, há uma boa sistematização do ponto central que temos destacado aqui.

Até então temos vivido com a ideia de um futuro certo, de uma incerteza do presente e da opacidade do passado. É isto que está mudando diante de nossos olhos. Há uma presença marcante do passado no espaço público, que não é nova, mas que ganhou intensidade. Na atualidade, nós atravessamos uma grave crise de historicidade em função da crise da noção de futuro. Noção de futuro que põe em questão a postura clássica do historiador como intermediário entre o passado e o devir. Essa mudança na nossa relação com o futuro, a crise de todas as escatologias e, assim, o colapso das teologias, tem o efeito de modificar nossa relação com o passado, abrindo-o sobre um presente exposto, em uma forma de presentismo. Esta situação é marcada pelo desaparecimento gradual de toda cronosofia que dá um sentido imanente à "flecha do tempo". A busca por sentido deslocou a atenção para a ação no momento de sua realização. Isto colocou foco sobre o presente como detector de sentido relacionando-o com a memória, a comemoração, o patrimônio e a arquivização. A crise do futuro deixa cada vez mais indeterminado o que deve ser dignificado como histórico, gerando daí a indistinção daquilo que pode acionar o horizonte de expectativa. (DOSSE, 2012, p. 10-11)

A grave crise de historicidade para a qual Dosse nos chama a atenção não é sintoma de uma ausência de interesse social pelo passado - como fica evidente no argumento de Huyssen -, mas sim do desgaste da concepção moderna de história ante o interesse do público comum - em situação oposta àquela descrita por Reinhart Koselleck, 
trazida na primeira seção deste artigo, no alvorecer da época contemporânea, segundo a qual "a configuração do conceito moderno, reflexivo de História, se deu tanto através de discussões científicas quanto através de diálogos político-sociais do cotidiano" (KOSELLECK, 2013, p.186) e "a gênese do conceito moderno de História coincide com a sua função social e política - sem naturalmente se limitar a ela" (KOSELLECK, 2013, p. 186). Na atualidade, é possível dizer que o conhecimento histórico possui ainda múltiplos sentidos e interfaces sociais e políticas, mas a questão é saber se elas ainda conseguem coincidir com os termos do conceito moderno de História, especialmente em sua capacidade de antecipação de futuros estáveis.

Se à historiografia escolar cabe, como afirmam Guimarães (2009) e Teixeira, Magalhães e Rocha (2009), suprir carências de orientação no mundo, parece redobrado o desafio de pensá-la nos termos deste debate atual de presente alargado, futuro encoberto e um arsenal de possibilidades abertas pela oficina da história, de experiências e conhecimento sobre o passado. Em outras palavras, é possível pensar em preenchimento da carência de orientação para além dos termos da concepção moderna de história? Eis um ponto que mereceria espaço e fôlego maior do que este de que dispomos aqui. Por ora, ocupou-nos prioritariamente problematizar o lugar e o potencial de exploração do tempo presente na aula de história, em seus limites e possibilidades, como contínua presença e como fuga.

\section{3. À guisa de conclusão: a potencialidade da mobilização do tempo presente na aula de história}

O tempo presente dirige e orienta a história ensinada na escola e este é um traço inevitável que atravessa e constitui a história do ensino de história. O primado da formação, incompleto em si, pois refeito a partir de cada situação do devir cotidiano em que é requisitado, igualmente critério estável da forma pedagógica de produção do conhecimento histórico, também posiciona o tempo presente no centro. Afinal, a meta formadora para a vida em público é circunscrita e responde ao contexto presente em que está inserida. 
Reconhecendo o valor do tempo presente na história ensinada, este artigo analisou a história da conformação desta centralidade, de modo que os limites e potencialidades da mobilização do tempo presente na aula de história, no contexto contemporâneo, pudessem ser compreendidos à luz das vinculações com esta história e das circunstâncias peculiares da cultura histórica atual. Ao sustentar o quanto a presença do presente se constitui como atributo necessário à aula, de modo a despertar formas de inteligibilidade e produção de sentido histórico, o artigo assinalou a importância de potencializar tal presença por meio da aproximação com a formulação de Nicole Loraux, sobre o exercício continuado de um "anacronismo controlado" na operação historiográfica, estendido aqui à aula de história. Se descontrolada, a leitura retrospectiva/anacrônica esvazia a compreensão do passado como espaço de experiência marcado pela diferença, inviabilizando a leitura de mundo do presente pela égide da crítica e da desnaturalização, princípios caros à historiografia escolar - renovados em tempos, como os atuais, de ampliação do enfrentamento da pluralidade e da diferença cultural em âmbito público. Sem ponderação e discernimento crítico, o tempo presente mobilizado na aula pode suspender do conhecimento histórico a sua capacidade de refletir sobre as permanências, estruturas e o "fundo permanente comum" que atravessa os séculos - nos termos de Marc Bloch, sem o qual o estudo da história se torna uma coleção isolada de tempos presentes, reiterada sucessão de presentes superficiais em contínua superação.

\section{Referências}

ARAÚJO, Ricardo Benzaquen de. História e Narrativa. In: MATTOS, Ilmar Rohloff de (Org.). Ler e escrever para contar. Rio de Janeiro: Access, 1998.

ARAÚJO, Ricardo Benzaquen de. Ronda noturna: narrativa, crítica e verdade em Capistrano de Abreu. Estudos Históricos, Rio de Janeiro, v.1, n.1, p.28-54. 1988

ARAUJO, Valdei Lopes de ; RANGEL, Marcelo de Mello. Apresentação - Teoria e história da historiografia: do giro linguístico ao giro ético-político. Historia da Historiografia Ouro Preto, n. 17, abr., p. 318-332, 2015. 
ARAÚJO, Valdei Lopes de. A experiência do tempo: conceitos e narrativa na formação nacional brasileira (1813-1845). São Paulo: Huicitec, 2008.

ARENDT, Hannah. Entre o passado e o futuro. São Paulo: Perspectiva, 2003.

BENJAMIN, Walter. Sobre o conceito de história In: BENJAMIN, Walter O anjo da história. Belo Horizonte: Autêntica, 2013.

BITTENCOURT, Circe Maria Fernandes. Ensino de História: fundamentos e métodos. São Paulo: Cortez, 2004.

BLOCH, MARC. Apologia da história, ou, o ofício de historiador. Rio de Janeiro: Jorge Zahar Ed., 2002.

BRAUDEL, Fernand. Escritos sobre a história. São Paulo: Editora Perspectiva, 2007.

BURKE, Peter. A Escola dos Annales (1929-1989): a Revolução Francesa da historiografia. São Paulo: Fundação Editora da UNESP, 1997

CANCLINI, Nestor Garcia. Culturas híbridas: estratégias para entrar e sair da modernidade. 4. ed. São Paulo: UNESP, 2011.

CEZAR, Temistocles . Lição sobre a escrita da história. Historiografia e nação no Brasil do século XIX. Diálogos (Maringá), v. 8, p. 11-29, 2004

CHARTIER, Roger. À beira da falésia: a história entre incertezas e inquietudes. Porto Alegre: Editora Universidade / UFRGS, 2002.

DOSSE, François. História do tempo presente e historiografia. Revista Tempo e Argumento, v. 4, n. 1, p. 5-23, jan./jun., 2012,

COSTA, Fernando S. La cultura historica: uma aproximación diferente a la memória colectiva. Pasado y Memória: Revista de Historia Contemporánea, v.8, p. 267-286, 2009.

FERREIRA, Marieta de Moraes; DELGADO, Lucilia de Almeida Neves. Historia do tempo presente e ensino de história. Revista História Hoje, v. 2, n. 4, p. 19-34, 2013.

FERREIRA, Marieta de Moraes; DELGADO, Lucilia de Almeida Neves. História do tempo presente: desafios. Cultura Vozes, Petrópolis, v.94, n. 3, maio/jun., p.111-124, 2000.

GUIMARÃES, Manoel Escrita da história e ensino da história: tensões e paradoxos. In: ROCHA, Helenice; MAGALHÃES, Marcelo; GONTIJO, Rebeca (Orgs.). A escrita da história escolar: memória e historiografia. Rio de Janeiro: FGV Editora, 2009. 
GUIMARÃES, Manoel Nação e Civilização nos Trópicos: o IHGB e o projeto de uma história nacional. Estudos Históricos, Rio de Janeiro, n.1, 1988.

HARTOG, François. Regimes de historicidade: presentíssimo e experiências do tempo. Belo Horizonte: Autêntica, 2014.

HUYSSEN, Andreas. Seduzidos pela memória: arquitetura, monumentos, mídia. Rio de Janeiro: Aeroplano, 2000.

KOSELLECK, Reinhart. Estratos do tempo: estudos sobre história. Rio de Janeiro: Contraponto; Editora PUC-Rio, 2014.

KOSELLECK, Reinhart; MEIER, Christian; GÜNTHER, Horst; ENGELS, Odilo. 0 conceito de História. Belo Horizonte: Autêntica, 2013.

LEGOFF, Jacques. "Prefácio” In BLOCH, MARC. Apologia da história, ou, o ofício de historiador. Rio de Janeiro: Jorge Zahar Ed., 2002.

LOURAX, Nicole. Elogio do anacronismo. In: NOVAES, Adauto (Orgs.). Tempo e História. São Paulo: Companhia das Letras, 1992.

MAGALHÃES, Marcelo de S. História e cidadania: por que ensinar história hoje? In: ABREU, Martha; SOIHET, Rachel (Orgs.). Ensino de história: conceitos, temáticas e metodologia. Rio de Janeiro: Casa da Palavra, 2003, v. 1, p. 168-184.

MATTOS, Hebe. Racialização e cidadania no Império do Brasil. In CARVALHO, José Murilo de; NEVES, Lucia Bastos Pereira (Orgs.). Repensando o Brasil dos oitocentos. Rio de Janeiro: Civilização Brasileira, 2009.

MATTOS, Ilmar R. Do Império do Brasil ao Império do Brasil. In: Faculdade de Letras da Universidade do Porto (Org.). Estudos em homenagem a Luís Antonio de Oliveira Ramos. Porto: Universidade do Porto, 2004, v. 2, p. 727-736.

MATTOS, Ilmar Rohloff. O Tempo Saquarema. São Paulo: Hucitec, 2004.

MATTOS, Ilmar Rohloff. Mas não somente assim! Leitores, autores, aulas como texto e o ensino-aprendizagem de História. Tempo, v.11, n. 21, p. 5-16, 2007,.

MATTOS, Ilmar Rohloff. O gigante e o espelho. In: KEILA, Grinberg; RICARDO, Salles (Orgs.). O Brasil Imperial (1831-1870). v.2. Rio de Janeiro: Civilização Brasileira, 2009.

MONTEIRO, Ana Maria Ferreira da Costa. Professores de História: entre saberes e práticas. Rio de Janeiro, Editora Mauad, 2007. 
MONTEIRO, Ana Maria Ferreira da Costa. Tempo presente no ensino de história. In GONÇALVES, Márcia de A. (org) et al. Qual o valor da história hoje? Rio de Janeiro: Editora FGV, 2012

SALLES, Ricardo. Nostalgia imperial: a formação da identidade nacional no Brasil do Segundo Reinado. Rio de Janeiro: Topbooks, 1996.

SARLO, Beatriz. Tempo passado: cultura da memória e guinada subjetiva. São Paulo: Companhia das Letras; Belo Horizonte: UFMG, 2007.

SOUSA, Francisco Gouvea. Revolta e proclamação como molduras da história: escrita da história e olhares para a República entre os sócios do IHGB. História da historiografia, Ouro Preto, n. 18 , p. 213-230, ago., 2015,

SILVA, Rogério Forastieri. A história da historiografia e o desafio do giro lingüístico História da historiografia, Ouro Preto, n. 17, abr., p. 377-395, 2015.

STAROBINSKI, Jean. As máscaras da civilização: ensaios. São Paulo, Companhia das Letras, 2001.

TEIXEIRA, Rebeca Gontijo ; ROCHA, Helenice Aparecida Bastos ; MAGALHÃES, Marcelo de S. . A aula como texto: historiografia e ensino de história. In: MAGALHÃES, Marcelo; ROCHA, Helenice; TEIXEIRA, Rebeca G (Orgs.) A escrita da história escolar: memória e historiografia. Rio de Janeiro: Editora da Fundação Getúlio Vargas, 2009, v. 1, p. 13-31.

TURIN, Rodrigo. Uma nobre, difícil e útil empresa: o ethos do historiador oitocentista. História da Historiografia, Ouro Preto, n. 02 , p. 12-28, mar.2009. 